\title{
Removal of Reactive Black 5 dye from aqueous solutions by coupled electrocoagulation and bio-adsorbent process
}

Behnaz Naraghi ${ }^{1}$, Mohammad Mehdi Baneshi ${ }^{2}$, Reza Amiri ${ }^{3}$, Amin Dorost ${ }^{4}$, Hamed Biglari ${ }^{5}$

${ }^{1}$ MSc. of Environmental Health, Senior Lecturer, Department of Environmental Health Engineering, School of Public Health, Birjand University of Medical Sciences, Birjand, Iran

${ }^{2} \mathrm{PhD}$. of Environmental Health, Assistant Professor, Department of Environmental Health Engineering, School of Public Health, Social Determinants of Health Research Center, Yasuj University of Medical Sciences, Yasuj, Iran

${ }^{3}$ Research Center for Environmental Determinants of Health (RCEDH), Kermanshah University of Medical Sciences, Kermanshah, Iran

${ }^{4}$ Students Research Committee, Torbat Heydariyeh University of Medical Sciences, Torbat Heydariyeh, Iran

${ }^{5}$ MSc. of Environmental Health, Senior Lecture, Department of Environmental Health Engineering, School of Public Health, Social Development \& Health Promotion Research Center, Gonabad University of Medical Sciences, Gonabad, Iran

\section{Type of article: Original}

\begin{abstract}
Background: Textile wastewater contains a significant amount of bio dye compounds including Reactive Black 5 (RB5) as an Azo dye that causes serious damage to the environment and aquatic life in receiving water resources. It is estimated that approximately $15 \%$ of the dyestuff is discharged into water bodies and $50 \%$ of those are Azo dyes.

Objective: The aim of this study was to examine the effectiveness of combining electrocoagulation and bioadsorption methods using the active carbons from Kenya tea waste to remove RB5 from aquatic solutions.

Methods: Experiments were done in wastewater and the Wastewater laboratory of Gonabad University of Medical Sciences in 2017. Initially, iron electrodes were installed in a $1 \mathrm{~L}$ glass container and connected to electrical power with primary dye concentration of $500 \mathrm{mg} / \mathrm{l}$, EC 1000-3000 $\mu \mathrm{s} / \mathrm{cm}$, adsorbent dosage of 0.2-1.0 $\mathrm{mg} / \mathrm{l}, \mathrm{pH} 2-9$ and electrical potential $30 \mathrm{~V}$. After that, the samples were collected at twenty-minute intervals until the eightieth minute. Performance of dye removal was measured using spectrophotometer techniques $(597 \mathrm{~nm})$. Finally, the data were analyzed by descriptive statistics using Microsoft Excel 2017 version.

Results: The findings of this study demonstrated that the highest simultaneous removal performance (96\%) was obtained by $\mathrm{pH} 6,80$-minute reaction time, and EC $3000 \mu \mathrm{s} / \mathrm{cm}$. With the increasing of reaction time, the energy consumption, electrodes wear, $\mathrm{pH}$, final temperature of effluent, and removal efficiency would increase. Adsorption process could play a small role in the removal of the dye, while it was very effective in improving the performance of the electrocoagulation process.

Conclusion: A combination of the electrocoagulation and adsorption processes can be adopted as an efficient and economical way to treat effluents contaminated with dyestuff.

Keywords: Reactive Black 5, Electrocoagulation, Bio-adsorbent, Aqueous solutions, Tea adsorbent
\end{abstract}

\section{Introduction}

Textile industries are highly dependent on water and consequently produce a significant amount of effluent. The effluent contains large amounts of bio dye materials. Approximately $50 \%$ of the dyes used in the textile industry are Azo dyes that are also widely used in other industries such as printing, pharmaceutical, and toy industries $(1,2)$. It is estimated that about $15 \%$ of the dyestuff is discharged into the environment as effluent of the dying process $(3,4)$.

\section{Corresponding author:}

Hamed Biglari, Department of Environmental Health Engineering, School of Public Health, Social Development \& Health Promotion Research Center, Gonabad University of Medical Sciences, Gonabad, Iran.

Tel: +98.5157225027, Fax:+98.5157223814, Email: Biglari.h@gmu.ac.ir

Received: February 12, 2017, Accepted: May 26, 2018, Published: July 2018

iThenticate screening: August 28, 2017, English editing: June 12, 2018, Quality control: June 14, 2018

This article has been reviewed / commented by three experts

Funding / research project approval: Grant no. 95/5 (year 2016)

(C) 2018 The Authors. This is an open access article under the terms of the Creative Commons Attribution-NonCommercialNoDerivs License, which permits use and distribution in any medium, provided the original work is properly cited, the use is non-commercial and no modifications or adaptations are made. 
Discharge of dye effluent into rivers and lakes attenuates quality of water, decreases oxygen transfers into water and solvability of gasses, increases toxicity, causes cancer, and mutates animals and humans (5). Therefore, dye removal from the effluents is of great importance. Following scientific advances in the manufacturing of textile dyes, new dyes have been introduced on the market that bring better dye specifications with higher stability (6). However, stable dyestuff is more resilient to biological and chemical decomposition processes (7). The majority of the dyestuff employed in textile industries cannot be decomposed by treatment processes such as coagulation and chemical precipitation $(8,9)$. In addition, these processes are faced with other constraints and problems such as high cost, low performance, and production of large amounts of sludge (10). In this study, we attempted to investigate the effects of electrocoagulation and adsorption processes using a coupling technique for possibility to increase the pollutant removal efficiency. So far, this method has been investigated in studies regarding pollutant removal such as chromium (11), fluoride (12), and acid dye (13). In this study, Reactive Black 5 dye from aqueous solutions by coupled electrocoagulation and a new form of bio-adsorbent process under different conditions have also been investigated. The electrochemical process is considered as environmentally friendly and low cost and is a competitive method compared to other methods. Other advantages of this method are the inexpensive equipment needed to implement the method, production of small volume of sludge with low water content and high water absorption capacity, and small space requirement (14). To destabilize suspended and colloid materials by electrochemical coagulation processes, electricity, and iron/aluminum electrodes are needed (15). The electrodes are decomposed via electrolysis process in the electrocoagulation process to produce metal hydroxides that coagulate suspended particles, which eventually, destabilize colloid particles or contaminants through precipitation (16). M is the anode metal and $\mathrm{n}$ is the number of transferred electrons in the oxidation and reduction reactions (17). Adsorption is the augmentation process of particles where the two phases meet. This method can be considered as one of the efficient and economical methods to remove pollutants and dye from aquatic solutions. The process uses carbonated/non-carbonated (powder and granular) in activated and non-activated forms (e.g. ash, bentonite, phosphate, cellulose, biomass, charcoal, and porcelain soil (18). Recently, researchers have paid more attention to improving performance and removing the obstacles by combining two or more processes. There have been studies on the combined electrocoagulation and adsorption processes $(11,13,19)$. The present study has been an attempt to apply the two processes and overcome the problems by using the two processes for disintegrating adsorbent powder from water and provide clarity in the electrocoagulation process to remove Reactive Black 5 dye from aquatic solutions.

\section{Material and Methods}

\subsection{Materials and Methods}

The chemical materials including RB5 dye (C26H21Na4N5O19S6 [CASRN 17095-24-8]), sodium hydroxide, and chloridric acid were procured from Merck Company (Germany). Distilled water (HPLC) was used in the experiment. The stock solution of the dye $(1000 \mathrm{mg} / \mathrm{l})$ was prepared by dissolving a specific amount of RB5 dye powder (55\%). The $\mathrm{pH}$ value was set by Denver Ultra basic-UB10 (USA) using chloridric acid and $1.0 \mathrm{~N}$ sodium hydroxide. EC was checked using WTW-Cond 1310 (Germany) at 1000, 1500, 2000, 2500, and $3000 \mu \mathrm{s} / \mathrm{cm}$ using $1.0 \mathrm{~N} \mathrm{KCL}$.

\subsection{Adsorbent preparation}

Tea waste (granulated, mesh 60 , dried) was prepared from Kenyan small grain tea supplied by an ice tea factory in Iran. To remove probable dyestuff and contaminants, the tea was pickled for four hours in phosphoric acid (1:3) and then rinsed until neutral $\mathrm{pH}$ was achieved. After that, the tea waste was dried at $120^{\circ} \mathrm{C}$ for $24 \mathrm{~h}$. Then, it was converted into ash at $600^{\circ} \mathrm{C}$ for $60 \mathrm{~min}$ in a horizontal electrical furnace (Alfa) in absence of oxygen. The obtained ash was stored in a cool sealed desiccator. Figure 1 illustrates the SEM adsorbent images before and after adsorbing RB5 dye.

\subsection{Experiment}

Experiments were done in the Wastewater laboratory of Gonabad University of Medical Sciences in 2017. A glass container with length, width, and height of $10 \mathrm{~cm}, 12 \mathrm{~cm}$, and $13 \mathrm{~cm}$ respectively $(1 \mathrm{~L})$ was used to affix the plane iron electrodes $(10 \times 11 \mathrm{~cm})$ to form a bipolar system with a $2 \mathrm{~cm}$ gap in between. The electrodes were connected to a source (30V-Micro). Before switching the source ON, the samples of synthetic effluent $(500 \mathrm{mg} / \mathrm{l})$ were poured into a reactor and mounted on a magnetic mixer at low rpm after setting pHs on 2, 3, 4, 5, 6, 8, 9 and EC on 1000, 15000, 2000, 2500, and $3000 \mu \mathrm{s} / \mathrm{cm}$. Afterwards, electrocoagulation and adsorption experiments were performed simultaneously and separately. Dye removal performance was determined by collecting $20 \mathrm{~mL}$ specimens at twentyminute intervals over eighty minutes using spectrometer (Thermo Scientific Helios Epsilon UV/VIS- $597 \mathrm{~nm}$ ). The amount of decomposed iron in the reactor was measured before and after the process using Faraday's law and based on weight comparison. Finally, the data were analyzed by descriptive statistics using Microsoft Excel 2017 version. 


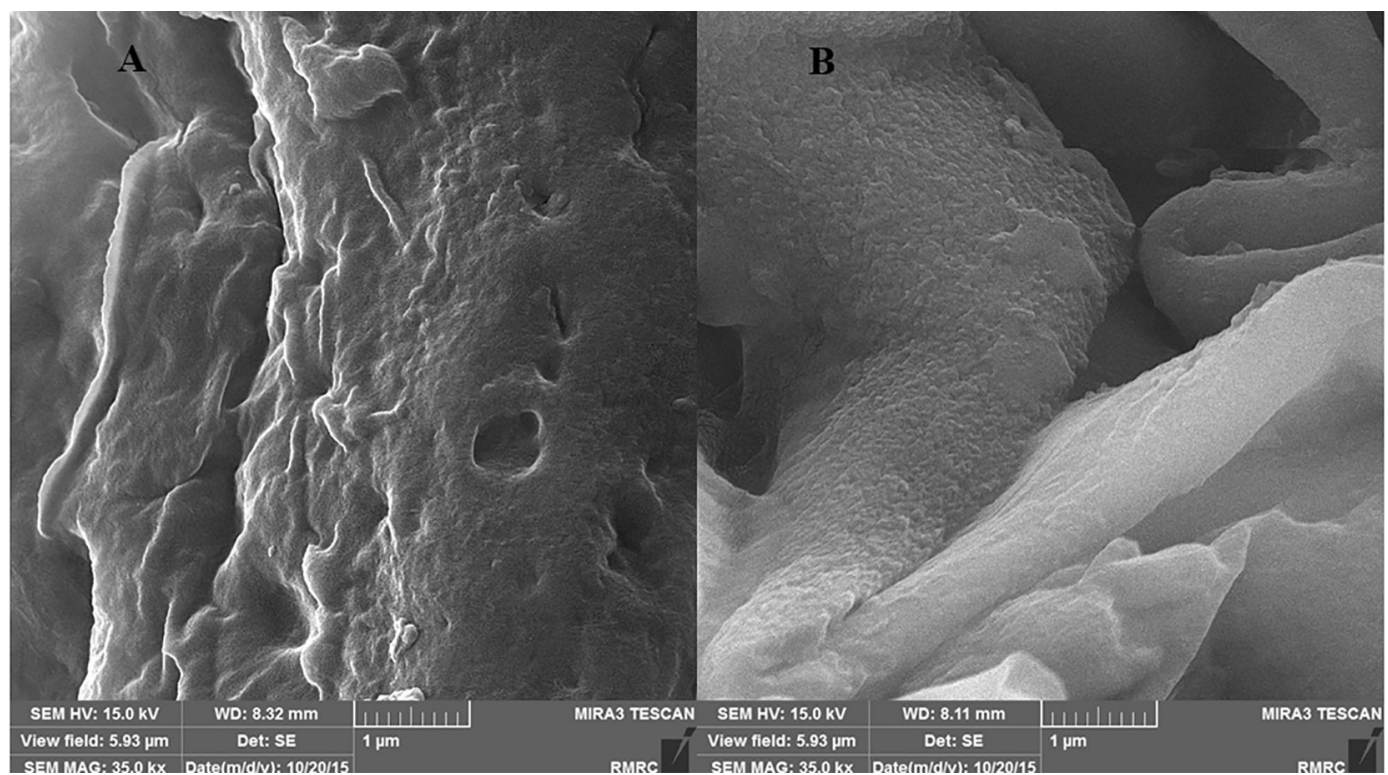

Figure 1. Scanning electron microscope micrograph activated carbon of Kenya Tea Pulp. A: before and B: after Reactive Black 5 dye adsorption

\section{Results and discussion}

\subsection{The effects of $\mathrm{pH}$}

The primary $\mathrm{pH}$ from a solution is notably effective in the performance of chemical reactions and electrocoagulation process for removing bio contaminants from aquatic solutions. Change in the final $\mathrm{pH}$ from the effluent, like the primary $\mathrm{pH}$, is of great importance concerning environmental standards and regulations for discharging effluents (20-22). The final $\mathrm{pH}$ from a solution might change during the electrocoagulation and adsorption processes. The change is subject to material of the electrode, absorbers, and $\mathrm{pH}$ of the effluent (10). The effects of changes in the primary $\mathrm{pH}$ from 2 to 9 on performance of electrocoagulation process and the effect of the final $\mathrm{pH}$ on the primary $\mathrm{pH}$ rate using iron electrode are shown in Figure 2.

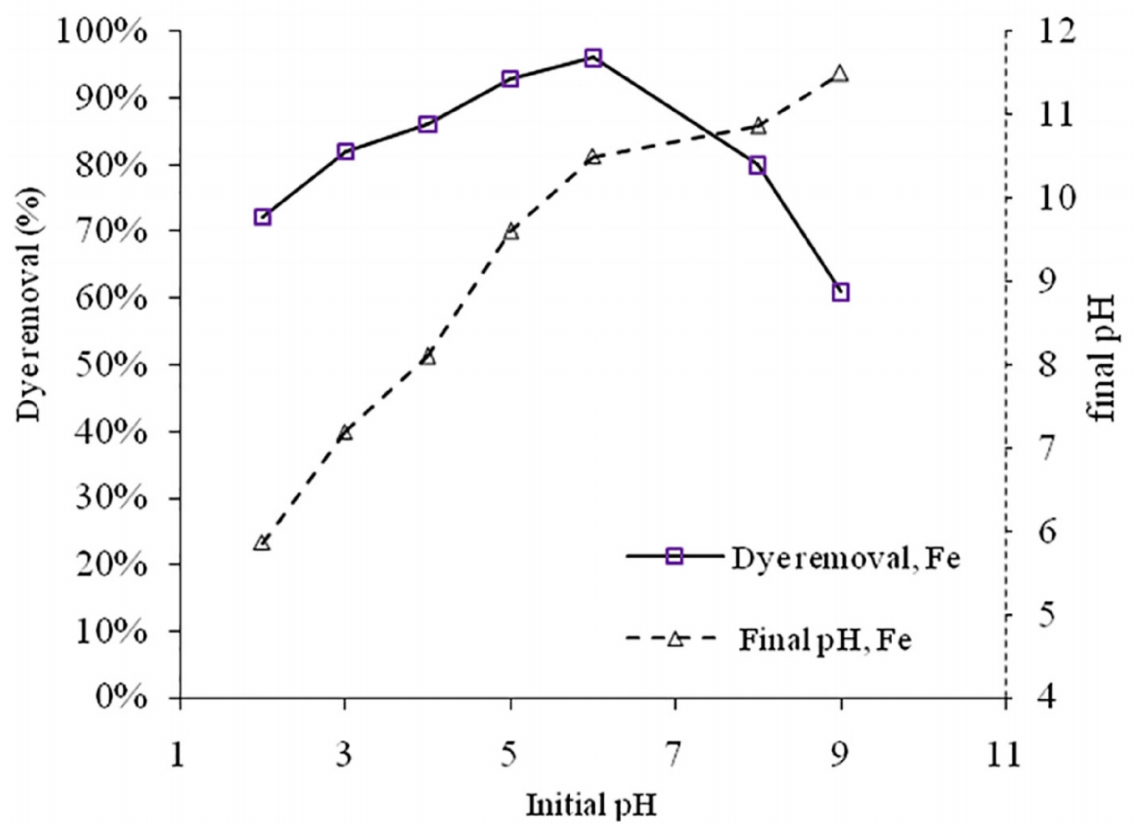

Figure 2. Effect of initial $\mathrm{pH}$ on dye removal and final changing of it (30 V, $1 \mathrm{~g} / 1$ adsorbent, EC $3000 \mu \mathrm{s} / \mathrm{cm}$ and $80 \mathrm{~min})$

The Highest removal performance was about $96 \%$ with $\mathrm{pH} 6$. In addition, the results showed that the final $\mathrm{pH}$ was on average 3.8 units higher than the primary $\mathrm{pH}$, so that after the process, the effluent was discharged as alkali 
(Figure 2). The effect of temperature changes and the final $\mathrm{pH}$ over time is shown in Figure 3. The results revealed that with increasing the reaction time to eighty minutes, the final temperature of the process increased from 25.7 to $48.9{ }^{\circ} \mathrm{C}$ and $\mathrm{pH}$ increased from 5 to 9 (correlation coefficient of 96\%) (Figure 3). Adsorption of RB5 with the primary $\mathrm{pH}$ ranged from 5 to 9 is illustrated in Figure 4. The results indicated that higher adsorption performance was achieved by the primary $\mathrm{pH}$ of 5 equal to $7.82 \%$, while the ratio of the residual dye to the primary dye content was 0.92 . Kannan et al. reported that the rate of the final $\mathrm{pH}$ to the primary $\mathrm{pH}$ increased with the reaction time so that $\mathrm{pH}$ of electrocoagulation process with and without adsorbent increased from 4.78 to 6.41 and 5.96, respectively (10). They explained their findings by highlighting the reaction between the generated hydrogen gas with $\mathrm{Cl}_{-}, \mathrm{NO}_{3}-$, and $\mathrm{HCO}_{3}$ - and decomposition of $\mathrm{Al}(\mathrm{OH})_{3}$ to strong $\mathrm{OH}$ - ions. Ghalwa et al. argued that using iron electrodes at alkali $\mathrm{pH}$ improved removal process due to the decrease in iron ions decomposition and formation of iron (II) hydroxide forms that are adsorbents of dye molecules (23). In addition, removal performance decreased at alkali $\mathrm{pH}$ because hydroxide ions were oxidized at the anode, conversion of $\mathrm{Fe}^{+2}$ to $\mathrm{Fe}^{+3}$ forms, and formation of $\mathrm{Fe}(\mathrm{OH})_{6}{ }^{3}-$ and $\mathrm{Fe}(\mathrm{OH})^{4}$-. Consistent with our results, they reported that the highest removal performance was achieved by the primary $\mathrm{pH}$ equal to 6 . Therefore, $\mathrm{pH}$ of 6 was taken as the optimum $\mathrm{pH}$ for the simultaneous processes of electrocoagulation with iron electrode and adsorption.

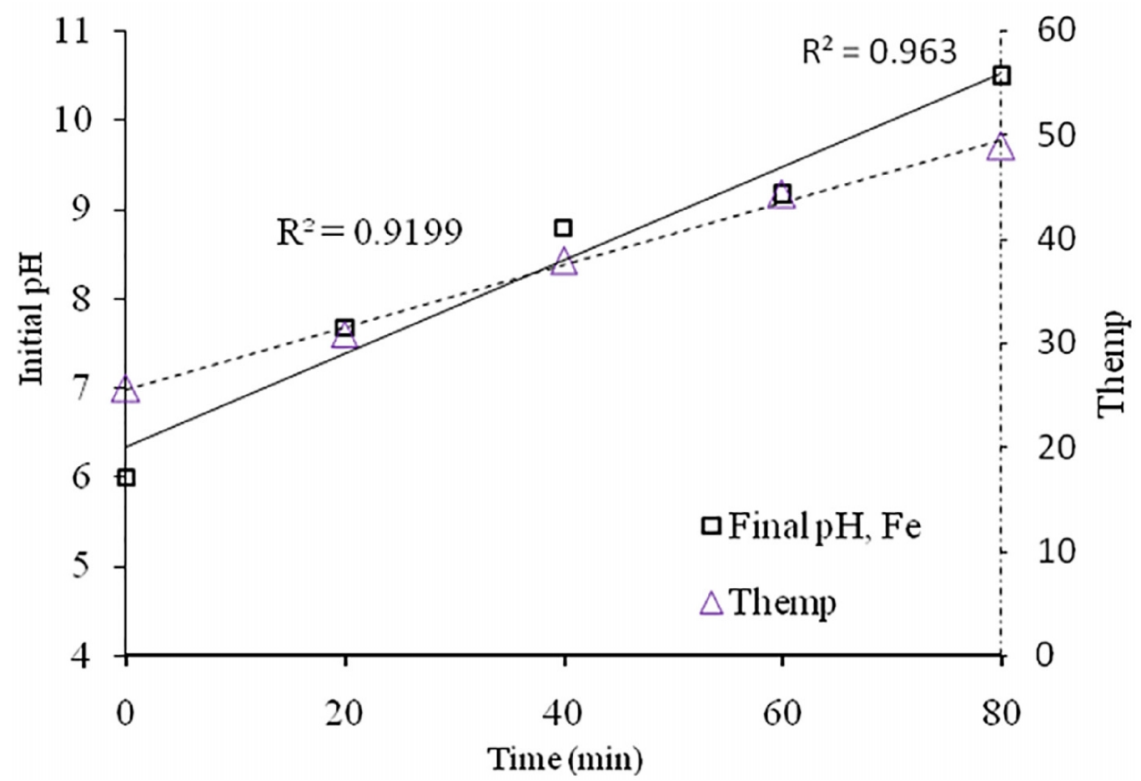

Figure 3. Temperature change relative to initial $\mathrm{pH}$ and temperature ( $30 \mathrm{~V}$, adsorbent $1 \mathrm{~g} / \mathrm{l}$, EC $3000 \mu \mathrm{s} / \mathrm{cm}$ and Dye $500 \mathrm{mg} / \mathrm{l})$

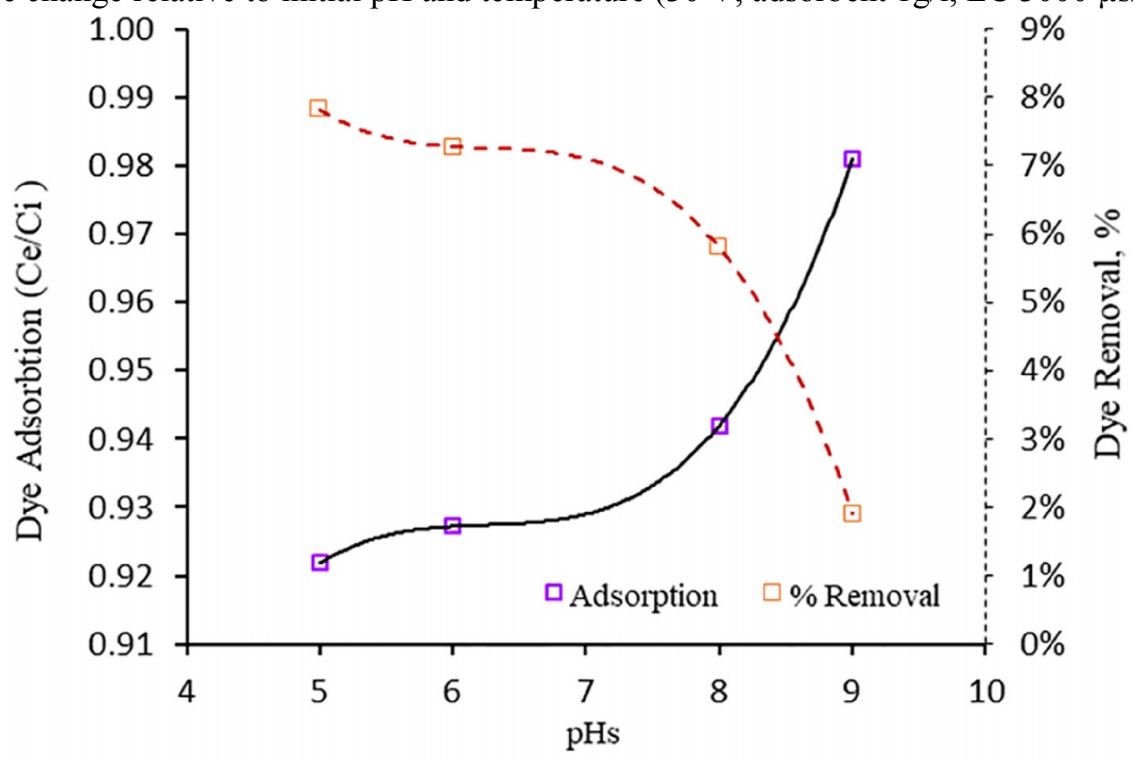

Figure 4. Effect of initial $\mathrm{pH}$ on rate of adsorption (adsorbent $1 \mathrm{~g} / \mathrm{l}, 80 \mathrm{~min}$ ) 


\subsection{The effects of adsorbent dose}

The effect of adsorbent dose for simultaneous and separate use of electrocoagulation and adsorbent is shown in Figure 5. The results showed that with the increase in adsorbent dose from 0.2 to $1 \mathrm{~g} / \mathrm{l}$, performance of the dye removal increased significantly and the rate of the residual dye to the initial dye content decreased from 0.99 to 0.92 (Figure 5). This rate, with the use of iron electrode, adsorbent dose of $1 \mathrm{~g} / 1$ and $\mathrm{pH}=6$ was 9.27 and when the two processes were simultaneously applied, it improved by 0.020 . Figure 6 shows the results of the processes separately and simultaneously. The results demonstrated that the rate of initial dye concentration to residual dye using iron electrode without and with adsorbent, were 0.049 and 0.020 , respectively (Figure 6). Bazrafshan et al. reported that an increase in the adsorbent dose from 0.1 to $0.8 \mathrm{~g} / \mathrm{l}$ increased removal performance. With the increasing of the number of the available sites for adsorption process, with adsorbent dose of $0.8 \mathrm{~g} / \mathrm{l}$, COD removal performance increased by $99 \%$ (19). Sebastian Secula et al. argued that increase of adsorbent dose from $0.25 \mathrm{~g} / 1$ to 0.5 and higher, while using the two processes simultaneously, resulted in a considerable increase in Carmine dye removal up to $99 \%$ (13). Alizadeh et al. reported that removal performance decreased by an increase in primary dye content when iron electrodes were used due to the decrease in reaction rate, while $\mathrm{pH}$ is a major effective parameter in the removal. In addition, they argued that high concentration of the contaminants in the adsorption process resulted in saturation of adsorption on the adsorbent and a decrease in performance (3).

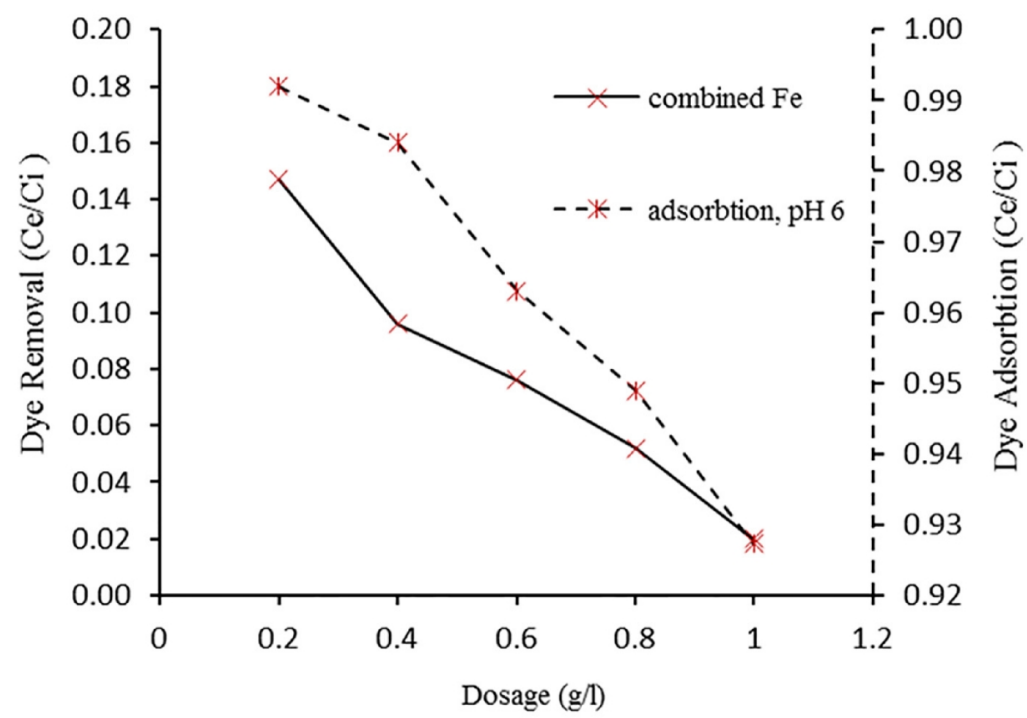

Figure 5. Effect of change of adsorbent dosage on adsorption and electro-adsorption process ( $30 \mathrm{~V}$, Dye $500 \mathrm{mg} / \mathrm{l}$, EC $3000 \mu \mathrm{s} / \mathrm{cm}, \mathrm{pH} 6)$

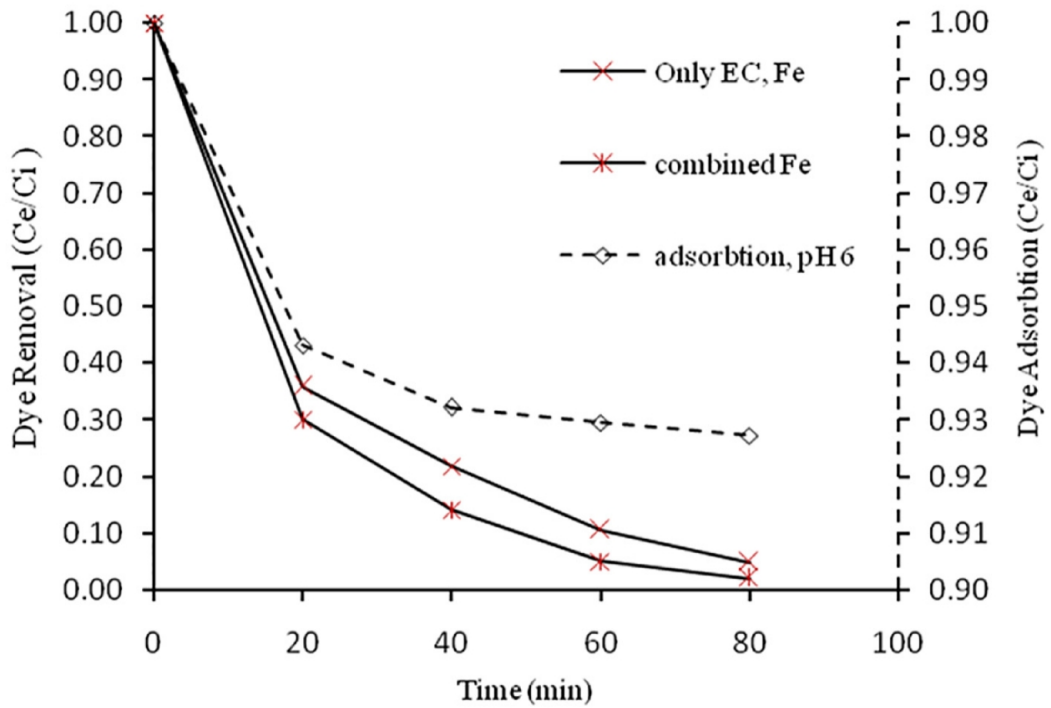

Figure 6. Effect of electrocoagulation and adsorption process separately and coupled on dye removal $(30 \mathrm{~V}$, adsorbent 1 g/l, Dye $500 \mathrm{mg} / \mathrm{l}$, EC $3000 \mu \mathrm{s} / \mathrm{cm}, \mathrm{pH} 6)$ 


\subsection{The effect of reaction time}

In almost all studies, reaction time has been considered as one of the main parameters in chemical reactions. In addition to the decrease in costs, reaction time increases both performance and feasibility of the processes $(24,25)$. The effect of changes in reaction time on energy consumption in dye removal by iron electrode is shown in Figure 7. The results indicated that the increase in exposure time and energy consumption resulted in a decrease in concentration of residual dye, so, $0.32 \mathrm{kWh}$ of energy was used for removing one gram of dye. Electro-adsorption decreased the final concentration of dye using iron electrode from 500 to $10 \mathrm{mg} / 1$ (Figure 7). The effect of the reaction time on iron electrode wear in removal of each gram of dye is illustrated in Figure 8. The results indicated that $2.39 \mathrm{gr}$ of e iron electrode was consumed (production of coagulant) for removal of each gram of dye after the eightieth minute of the reaction (Figure 8). Dalvand et al. reported that the increase of reaction time increased energy consumption for dye removal of $99.1 \%$ (Voltage $=20 \mathrm{~V} ; \mathrm{T}=75 \mathrm{~min}$; and $\mathrm{E}=1.516 \mathrm{kWh} / \mathrm{m}^{3}$ ). They explained their results by mentioning the increase in the electrical current in the electrodes (26). Rahmanir et al. (2013) reported that an increase in reaction time increased removal performance so that the latter increased from $89.74 \%$ to $95.18 \%$ when the former increased the reaction time from 22.17 to $28.10 \mathrm{~min}$. As they argued, this was due to a higher rate of $\mathrm{Fe}$ ions generation from iron electrodes and formation of adequate iron hydroxide precipitate (27). Alizadeh et al. argued that longer process time is needed to remove contaminants when the primary concentration of the contaminants increases (3). The diluted solution forms a disuse layer around the electrode and increases the reaction rate, while in dense solutions, the diffuse layer has no effect on the rate of distribution or migration of metallic ions toward the electrode surface. Therefore, removal performance decreased with a higher concentration of the contaminants (3). Our results, consistent with other studies, suggested that an increase in reaction time from 0 to $80 \mathrm{~min}$ increased energy consumption, iron electron wear, and removal performance. So, the highest performance was achieved at the eightieth minute and then the procedure was stopped due to economic concerns.

\subsection{The effects of $E C$}

The higher the ionic power of water, the higher the current needed for a fixed voltage; in other words, by keeping the current constant, an increase in EC leads to the decrease of voltage (28). The effect of changes in EC on dye removal performance with iron electrodes using the electrocoagulation process is shown in Figure 9. The results indicated that an increase in EC of the reactor increased dye removal performance (Figure 9). The effect of changes in the primary value of EC on consumption of electrical energy and the electrodes and the dye removal is presented in Figure 10. The results showed that energy consumption and electrode wear increased with increase in EC, and consequently, the increase in removal performance was observed. Therefore, the increase of EC from 1000 to $3000 \mu \mathrm{s} / \mathrm{cm}$ could lead to an increase in energy consumption from 0.2 to $0.32 \mathrm{kWh} / \mathrm{g}$. In addition, weight of solved electrode increased from 1.44 to $2.38 \mathrm{~g}$ for each gram of the dye removal (Figure 10). Bazrafshan et al. reported that by keeping the voltage at a constant level, the increase in EC led to an increase in energy and electrode consumption; so wear in electrode increased from 0.11 to $0.19 \mathrm{~kg} / \mathrm{g}$ when EC increased from 1000 to $3000 \mu \mathrm{s} / \mathrm{cm}$, and meanwhile, humic acid removal increased from 76.95 to $92.69 \%$. Bazrafshan et al. highlighted that increase in EC by adding $1,1.5,2$, and $4 \mathrm{~g} / 1$ of chloride potassium increased humic acid removal significantly, due to increase in formation of coagulator materials, and the size of flocs (20). Consistently, our results showed that increase in EC led to an increase in removal performance, and the optimum value of EC was $3000 \mu \mathrm{s} / \mathrm{cm}$.

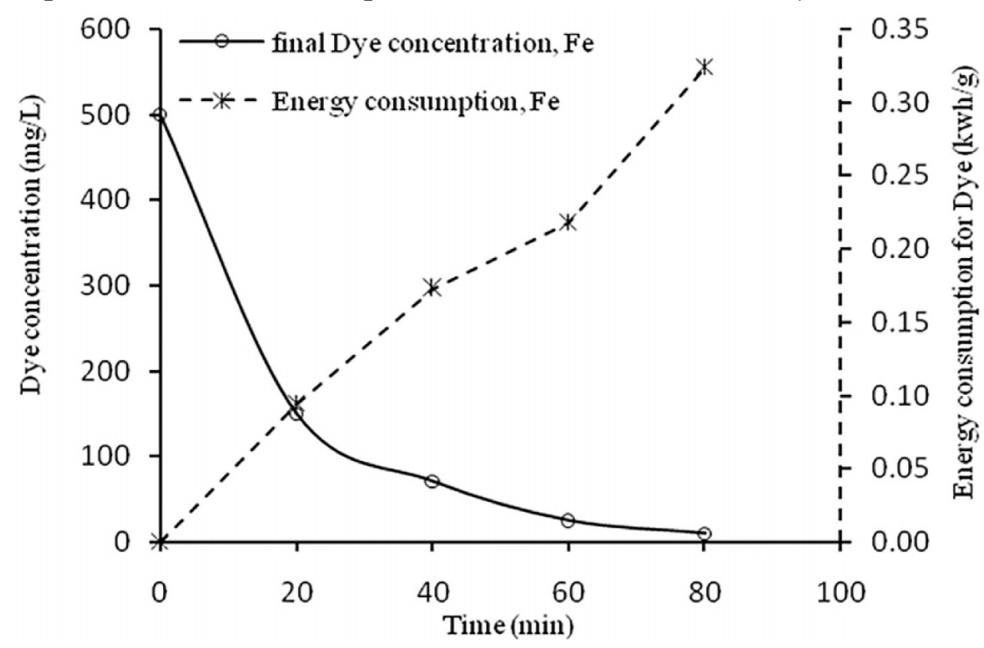

Figure 7. Effect of change of time on dye rate removal using iron electron ( $30 \mathrm{~V}$, adsorbent $1 \mathrm{~g} / 1$, Dye $500 \mathrm{mg} / 1$, EC 3000 $\mu \mathrm{s} / \mathrm{cm}, \mathrm{pH} 6)$ 


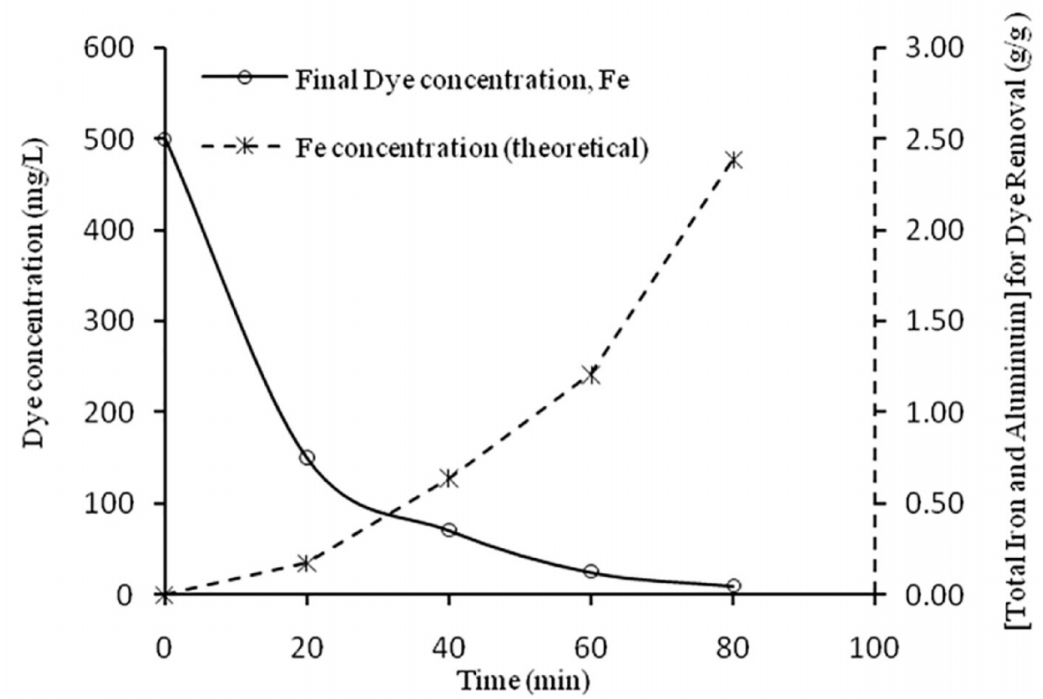

Figure 8. Effect of time on weight loss of iron electrode on dye removal (30 V, adsorbent 1 g/l, Dye 500 mg/l, EC 3000 $\mu \mathrm{s} / \mathrm{cm}, \mathrm{pH}$ )

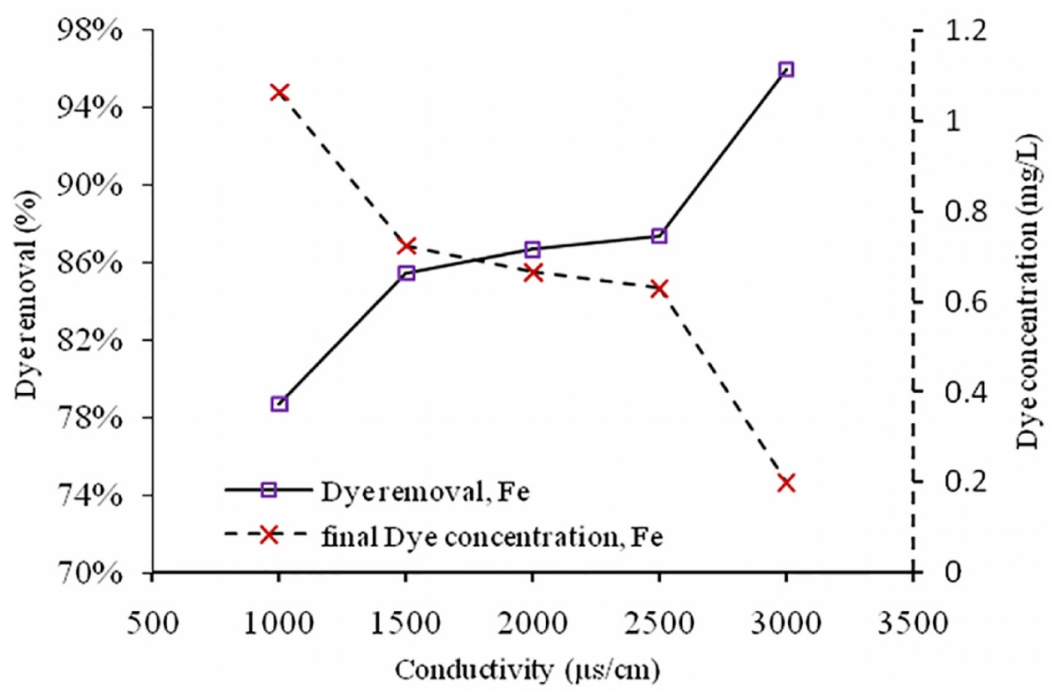

Figure 9. Effect of EC on dye removal (30 V, adsorbent $1 \mathrm{~g} / 1$, Dye $500 \mathrm{mg} / 1,80 \mathrm{~min}, \mathrm{pH} 6)$

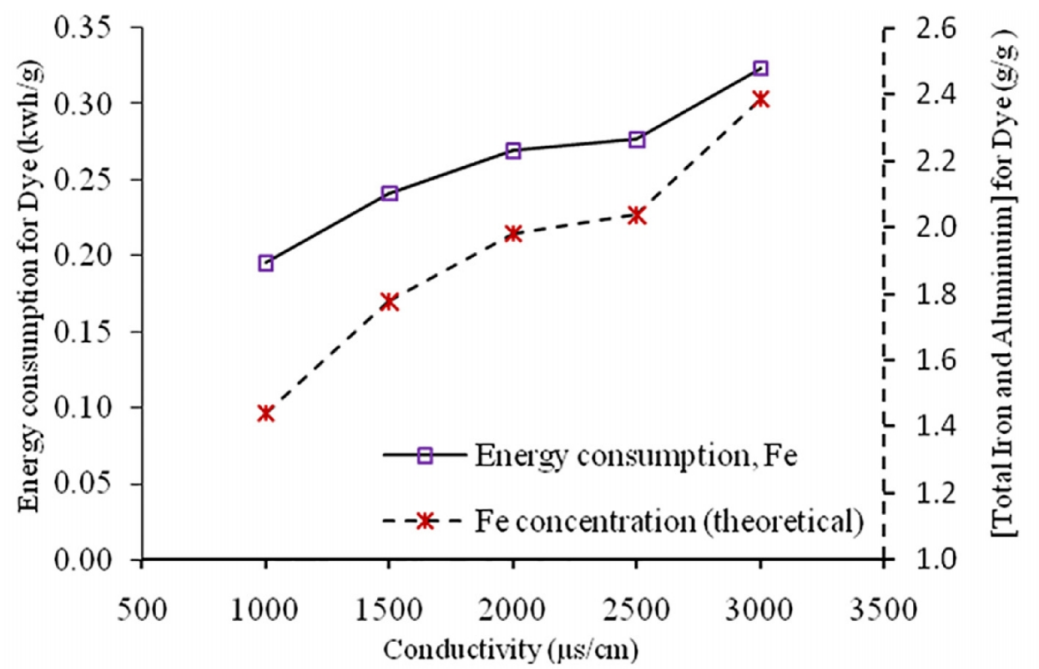

Figure 10. Effect of EC on energy consumption and iron loss (30 V, adsorbent $1 \mathrm{~g} / 1$, Dye $500 \mathrm{mg} / 1,80 \mathrm{~min}, \mathrm{pH} 6)$ 


\section{Conclusions}

This study examined the performance removal of RB5 by electrocoagulation and adsorption processes. The results indicated that RB5 removal performance increased by $96 \%$ via combining the two processes, using CTC tea waste as an adsorbent, reaction time of $80 \mathrm{~min}$, EC of $3000 \mu \mathrm{s} / \mathrm{cm}, \mathrm{pH}$ of 6 , initial dye concentration of $500 \mathrm{mg} / \mathrm{l}$, and adsorbent dose of $1 \mathrm{~g} / \mathrm{l}$. The results also showed increase in energy consumption and the electrode wear. Moreover, despite the negligible role of adsorption process in dye removal, combining the process with electrocoagulation could lead to considerable improvement in dye removal. Therefore, combining the electrocoagulation and adsorption processes can be adopted as an efficient and economical way to treat effluents contaminated with dyestuff.

\section{Acknowledgments:}

This project was funded and supported by Gonabad University of Medical Science, Grant no 95/5 (year 2016). The authors are grateful to the Deputy of Research \& Technology and the Department of Environmental Health Engineering, for logistical and technical support.

\section{Conflict of Interest:}

There is no conflict of interest to be declared.

\section{Authors' contributions:}

Amin Dorost (Birjand University of Medical Sciences, Birjand, Iran) and Reza Amiri (Yasuj University of Medical Sciences, Yasuj, Iran) were the respective statistical consultant and text editor of the study. Hamed Biglari (Gonabad University of Medical Sciences, Gonabad, Iran) was leader and advisor of the study experiments. Behnaz Naraghi (Birjand University of Medical Sciences, Birjand, Iran) was a performer, and designer for sampling and analyzing of the study.

\section{References:}

1) Salmani ER, Ghorbanian A, Ahmadzadeh S, Dolatabadi M, Nemanifar N. Removal of Reactive Red 141 Dye from Synthetic Wastewater by Electrocoagulation Process: Investigation of Operational Parameters. Iranian Journal of Health, Safety and Environment. 2016; 3(1): 403-11.

2) Shirmardi M, Mesdaghinia A, Mahvi AH, Nasseri S, Nabizadeh R. Kinetics and equilibrium studies on adsorption of acid red 18 (Azo-Dye) using multiwall carbon nanotubes (MWCNTs) from aqueous solution. Journal of Chemistry. 2012; 9(4): 2371-83. doi: 10.1155/2012/541909.

3) Alizadeh M, Mahvi AH, Mansoorian HJ. The survey of electrocoagulation Process for removal dye Reactive Orange 16 from aqueous solutions using sacrificial iron electrodes. Iranian Journal of Health, Safety and Environment. 2014; 1(1): 1-8.

4) Mahvi A, Ghanbarian M, Nasseri S, Khairi A. Mineralization and discoloration of textile wastewater by TiO 2 nanoparticles. Desalination. 2009; 239(1): 309-16. doi: 10.1016/j.desal.2008.04.002.

5) Vidal J, Villegas L, Peralta-Hernández JM, Salazar González R. Removal of Acid Black 194 dye from water by electrocoagulation with aluminum anode. Journal of Environmental Science and Health. 2016: 1 8.

6) Ashrafi SD, Rezaei S, Forootanfar H, Mahvi AH, Faramarzi MA. The enzymatic decolorization and detoxification of synthetic dyes by the laccase from a soil-isolated ascomycete, Paraconiothyrium variabile. International Biodeterioration \& Biodegradation. 2013; 85: 173-81. doi: 10.1016/j.ibiod.2013.07.006.

7) Dehghani MH, Mesdaghinia AR, Nasseri S, Mahvi AH, Azam K. Application of SCR technology for degradation of reactive yellow dye in aqueous solution. Water Qual Res J Can. 2008; 43(2/3): 1-10. doi: 10.2166/wqrj.2008.021.

8) Selcuk H, Bekbolet M. Photocatalytic and photoelectrocatalytic humic acid removal and selectivity of TiO 2 coated photoanode. Chemosphere. 2008; 73(5): 854-8. doi: 10.1016/j.chemosphere.2008.05.069. PMID: 18621411.

9) Wang KS, Chen HY, Huang LC, Su YC, Chang SH. Degradation of Reactive Black 5 using combined electrochemical degradation-solar-light/immobilized $\mathrm{TiO} 2 \mathrm{film}$ process and toxicity evaluation. Chemosphere. 2008; 72(2): 299-305. doi: 10.1016/j.chemosphere.2008.02.012. PMID: 18359062.

10) Kannan N, Karthikeyan G, Tamilselvan N. Comparison of treatment potential of electrocoagulation of distillery effluent with and without activated Areca catechu nut carbon. Journal of Hazardous Materials. 2006; 137(3): 1803-9. doi: 10.1016/j.jhazmat.2006.05.048. PMID: 16842910. 
11) Narayanan NV, Ganesan M. Use of adsorption using granular activated carbon (GAC) for the enhancement of removal of chromium from synthetic wastewater by electrocoagulation. Journal of Hazardous Materials. 2009; 161(1): 575-80. doi: 10.1016/j.jhazmat.2008.03.113. PMID: 18485589.

12) Khatibikamal V, Torabian A, Janpoor F, Hoshyaripour G. Fluoride removal from industrial wastewater using electrocoagulation and its adsorption kinetics. Journal of hazardous materials. 2010; 179(1): 276-80. doi: 10.1016/j.jhazmat.2010.02.089. PMID: 20347217.

13) Secula MS, Cagnon B, de Oliveira TF, Chedeville O, Fauduet H. Removal of acid dye from aqueous solutions by electrocoagulation/GAC adsorption coupling: Kinetics and electrical operating costs. Journal of the Taiwan Institute of Chemical Engineers. 2012; 43(5): 767-75. doi: 10.1016/j.jtice.2012.03.003.

14) Bazrafshan E, Biglari H, Mahvi AH. Phenol removal by electrocoagulation process from aqueous solutions. Fresenius Environmental Bulletin. 2012; 21(2): 364-71.

15) Daneshvar N, Ashassi-Sorkhabi H, Tizpar A. Decolorization of orange II by electrocoagulation method. Separation and purification Technology. 2003; 31(2): 153-62. doi: 10.1016/S1383-5866(02)00178-8.

16) Asgari G, Seid MA, Roshanaie GA, Sharifi Z, Mehralipur J, Shabanlo M. Electrocoagulation (ec) and electrocoagulation/flotation (ecf) processes for removing high turbidity from surface water using al and fe electrodes. 2013.

17) Bazrafshan E, Biglari H, Mahvi AH. Humic acid removal from aqueous environments by electrocoagulation process using iron electrodes. Journal of Chemistry. 2012; 9(4): 2453-61. doi: 10.1155/2012/876739.

18) Karcher S, Kornmüller A, Jekel M. Screening of commercial sorbents for the removal of reactive dyes. Dyes and pigments. 2001; 51(2): 111-25. doi: 10.1016/S0143-7208(01)00066-3.

19) Bazrafshan E, Alipour MR, Mahvi AH. Textile wastewater treatment by application of combined chemical coagulation, electrocoagulation, and adsorption processes. Desalination and Water Treatment. 2015: 1-13.

20) Bazrafshan E, Joneidi Jaafari A, Kord Mostafapour F, Biglari H. Humic acid removal from aqueous environments by electrocoagulation process duad with adding hydrogen peroxide. Iranian Journal of Health and Environment. 2012; 5(2): 211-24.

21) Mahvi A, Gholami F, Nazmara S. Cadmium biosorption from wastewater by Ulmus leaves and their ash. European Journal of Scientific Research. 2008; 23(2): 197-203.

22) Maleki A, Mahvi AH, Ebrahimi R, Zandsalimi Y. Study of photochemical and sonochemical processes efficiency for degradation of dyes in aqueous solution. Korean Journal of Chemical Engineering. 2010; 27(6): 1805-10. doi: 10.1007/s11814-010-0261-0.

23) Ghalwa NMA, Saqer AM, Farhat NB. Removal of Reactive Red 24 Dye by Clean Electrocoagulation Process Using Iron and Aluminum Electrodes. Journal of Chemical Engineering \& Process Technology. 2016; 2016.

24) Vijayakumar V, Saravanathamizhan R, Balasubramanian N. Electro oxidation of dye effluent in a tubular electrochemical reactor using TiO 2/RuO 2 anode. Journal of Water Process Engineering. 2016; 9: 155-60. doi: 10.1016/j.jwpe.2015.12.006.

25) Gholami-Borujeni F, Mahvi AH, Nasseri S, Faramarzi MA, Nabizadeh R, Alimohammadi M. Enzymatic treatment and detoxification of acid orange 7 from textile wastewater. Applied biochemistry and biotechnology. 2011; 165(5-6): 1274-84. doi: 10.1007/s12010-011-9345-5. PMID: 21892667.

26) Dalvand A, Gholami M, Ameri A, Mahmoodi N. Treatment of synthetic wastewater containing Reactive Red 198 by electrocoagulation process. Iranian Journal of Health and Environment. 2011; 4(1): 11-22.

27) Rahmani AR, Asgari G, Farrokhi M. Removal of Reactive Black 5 (RB5) Dye from Aqueous Solution using Adsorption onto Strongly Basic Anion Exchange Resin: Equilibrium and Kinetic Study. Iranian Journal of Health and Environment. 2013; 5(4): 509-18.

28) Biglari H, Bazrafshan E. Performance Evaluation of Electrochemical Process using Iron and Aluminum Electrodes in Phenol Removal from Synthetic Aqueous Environment. Iranian Journal of Health and Environment. 2013; 5(4): 445-56. 